\title{
TODIM Approach for Selection of Inventory Policy in Supply Chain
}

\author{
Prabjot Kaur (D), ${ }^{1}$ Bijay Lal Pradhan $\mathbb{D D}^{2}$ and Anjali Priya ${ }^{1}$ \\ ${ }^{1}$ Department of Mathematics, Birla Institute of Technology, Mesra, Ranchi, Jharkhand, India \\ ${ }^{2}$ Department of Statistics, Amrit Campus, Tribhuvan University, Kathmandu, Nepal
}

Correspondence should be addressed to Bijay Lal Pradhan; bijaya.pradhan@ac.tu.edu.np

Received 27 August 2021; Revised 16 October 2021; Accepted 18 January 2022; Published 7 February 2022

Academic Editor: Yuvraj Gajpal

Copyright (c) 2022 Prabjot Kaur et al. This is an open access article distributed under the Creative Commons Attribution License, which permits unrestricted use, distribution, and reproduction in any medium, provided the original work is properly cited.

TODIM-based multicriteria decision-making approach for assessing inventory policy in a Pythagorean fuzzy environment is proposed in this study. In supply chain, inventory appears in several forms. For effective supply chain, management businesses must choose an effective inventory policy. It is difficult to rank inventory policies. Inventory policy selection and evaluation include a procedure that can be thought about, checked after some time, and ideally improved through certain measures. Determination of the right inventory control policy is a challenge in the dynamic business environment as it enables organizations to gain an upper hand in terms of cost, quality, and service, which in turn provides a vital step in fulfilling the requirements of the customer. The multicriteria question has qualitative and quantitative factors that are vague and contradictory. Such variables are not necessarily clear and often suffer vagueness owing to the inconsistent existence of the gathered data. In the Pythagorean fuzzy setting, they are therefore considered to eliminate this vagueness by assigning membership and nonmembership roles to these factors. Finally, in this article, we performed a sensitivity analysis to demonstrate the stability of our model and to illustrate the utility of implementing such algorithms.

\section{Introduction}

Multicriteria decision taking (MCDM) is to choose the optimal alternative that best complies with multiple criteria from a finite set of alternatives. It is a major component of decision science, the principle of which has been widely applied in the fields of economics [1-5], management [6-10], and engineering [11-15]. Several methods have been proposed to deal with MCDM problems, such as TOPSIS (technique for order preference by similarity to an ideal solution) [16], ELECTRE (ELimination and Choice Expressing REality) [17], and PROMETHEE [18]. Eventually, with the growing complexity of the real-world MCDM problems, the risk attitudes of decision makers (DMs) need to be taken into account during the MCDM process. Initiated by Kahneman and Tversky, the prospect theory is a concise framework for underrisk decision taking. This theory encompasses three essential aspects [19]:
(1) Dependence on reference: the outcomes are represented by gains and losses according to an alternative guide.

(2) Sensitivity is reduced. The decision makers are riskaverse for profits. Yet, they are risk prime for losses.

(3) Aversion to failure: DMs are considerably more prone to losses than to gains [20].

Based on the prospect theory, Gomes and Lima [21] developed TODIM, the MCDM method, which is applicable to solving MCDM problems in which the psychological activities of DMs are taken into account.

Moreover, DMs are difficult to include detailed evaluations of alternatives for the complexity of MCDM problems. Fuzzy set theory [22] was applied to MCDM [23-25] to solve this problem, which provides a key means to explain the complex details. Later on, the intuitionist fuzzy set (IFS) [26], as the extension of the fuzzy set, was found to be highly efficient in handling MCDM problems under uncertainty 
[27-29], using a degree of membership and a degree of nonmembership, the sum of which is less than or equal to 1 , in order to simultaneously evaluate an object from the positive and negative sides. More recently, the Pythagorean fuzzy set (PFS) [30, 31] has emerged as an important method for representing MCDM problems with ambiguity. The PFS is often defined by the degree of membership and the degree of nonmembership, with a number of squares below or equal to 1 . The PFS is more general than the IFS. For example, if DM gives the membership degree and nonmembership degree as 0.8 and 0.6 , respectively, the PFS will solve the problems that the IFS cannot solve, and then, it is only valid for the PFS.

In other words, all the intuitive fuzzy degrees are part of Pythagorean fuzzy degrees, suggesting that the PFS is more efficient in dealing with ambiguous issues. We generally cannot provide the exact decisions about things because of the nature of the situations and the limits of our human thoughts. The PFS is well capable of representing this form of uncertainty through positive assessment and negative assessment, which can effectively express the confusion and uncertainty of DMs in MCDM problems. In this study, based on the immense superiority of the PFS, we plan to extend the TODIM approach to solving MCDM problems with Pythagorean fuzzy knowledge. Some previous studies have been careful to capture the attitudinal characters of DMs in MCDM issues [32-34], which are useful to depict the attitudes of DMs towards unknown and uncertain stuff. Uncertainty and risk are both common considerations which must be taken into account in the MCDM cycle for the magnitude of MCDM problems. Therefore, consideration of the risk attitudes of DMs in the MCDM issue is important to us. As previously implemented, TODIM [35] is a powerful method for taking psychological actions of DMs under pressure. Several researchers have used the fuzzy TODIM method to represent the complexity and challenge of the MCDM problems simultaneously in [36-43].

\section{Definitions and Formulas}

2.1. Pythagorean Fuzzy Sets. Pythagorean fuzzy sets were pioneered by Yager [24] to deal with vagueness with the membership grades as pairs satisfying the conditions of membership and nonmembership degree.

Let a set $X$ be a universal set; then, the Pythagorean fuzzy set $P$ is defined as

$$
P=\left\{\begin{array}{c}
<x, P\left(\mu_{p}(x), v_{p}(x)\right)>\mid x \in X \\
0 \leq\left(\mu_{p}(x)\right)^{2}+\left(v_{p}(x)\right)^{2} \leq 1
\end{array}\right\},
$$

where $\mu_{p}$ denotes the degree of membership, and $v_{p}$ denotes the degree of nonmembership function of elements $x$ to $P$.

$P\left(\mu_{p}(x), v_{p}(x)\right)$ can be represented as $\beta=P\left(\mu_{p}, v_{p}\right)$. Also, the square sum of $\mu$ and $v$ is not more than one, i.e., $\mu_{\beta}^{2}+v_{\beta}^{2} \leq 1$ where $\mu_{\beta}, v_{\beta} \in[0,1]$.

Some of the operations defined on PFS are as follows [44]:

$$
\begin{gathered}
\beta_{1} \oplus \beta_{2}=P\left(\sqrt{\mu_{\beta 1}^{2}+\mu_{\beta 2}^{2}-\mu_{\beta 1}^{2} v_{\beta 2}^{2}}, v_{\beta 1} \nu_{\beta 2}\right), \\
\beta_{1} \otimes \beta_{2}=P\left(\mu_{\beta 1} \mu_{\beta 2}, \sqrt{\nu_{\beta 1}^{2}+\nu_{\beta 2}^{2}-\nu_{\beta 1}^{2} \nu_{\beta 2}^{2}}\right), \\
\lambda \beta=P\left(\sqrt{1-\left(1-\mu_{\beta}^{2}\right)^{2}}, v_{\beta}^{2}\right), \lambda>0, \\
\beta^{\lambda}=P\left(\left(\mu_{\beta}\right)^{\lambda}, \sqrt{1-\left(1-v_{\beta}^{2}\right)^{2}}\right), \lambda>0 .
\end{gathered}
$$

2.2. The TODIM Approach. The TODIM approach [21], suggested understanding the psychological actions of DM, should address MCDM problems effectively. This method, based on the prospect principle, portrays the superiority of each alternative over others by constructing a multicriteria value function [19]. Let $C j=(j=1,2,3, \ldots)$ be the referred criteria, whose weight vector $w=\left(w_{1}, w_{2}, \ldots w_{n}\right)^{T}$ with $w_{j} \in[0,1],(j=1,2,3, \ldots)$. Then for alternatives $Y_{i \cdot(i=1,2, \ldots, m)}$, the decision matrix $A=\left(a_{i j}\right)_{n \times m}$ can be constructed, where $a_{i j}$ is the criterion value provided by DM over the alternatives $Y_{i}$ with respect to the criterion $C_{j}$. We define $w_{j r}=w_{j} / w_{r}$ as a relative weight of the criterion $C_{j}$ to $C_{r}$, and $w_{r}=\max \left\{w_{j} \mid j=1,2, \ldots, n\right\}$.In the following section, the method is presented.

\subsection{Pythagorean Fuzzy TODIM}

Definition 1. Let $\beta=\left(\mu_{p}, v_{p}\right)$ be a PFN; then, the score function of $\beta$ is defined as [45]

$$
S(\beta)=(\mu \beta)^{2}-(\nu \beta)^{2} .
$$

The larger the score is, the better the PFN is.

We know that score function is efficient to compare majority of PFNs. However, that may not always be the case. If we have $\beta_{1}=P(0.6,0.6)$ and $\beta_{2}=P(0.09,0.09)$, then $S\left(\beta_{1}\right)=S\left(\beta_{2}\right)=0$, but we know that these PFNs are not possibly the same [38].

Definition 2. Let $\beta=P\left(\mu_{\beta}, v_{\beta}\right)$ be a PFN; then, the accuracy of function $\beta$ is defined as [46]

$$
h(\beta)=\left(\mu_{\beta}\right)^{2}+\left(v_{\beta}\right)^{2},
$$

where $0 \leq h(\beta) \leq 1$. The greater the value of $h(\beta)$, the higher is the accuracy. We also express the hesitant degree of $x \in X$ as

$$
\pi_{\beta}(x)=\sqrt{1-\mu_{\beta}^{2}(x)-v_{\beta}^{2}(x)} .
$$

Also, $\pi_{\beta}^{2}+h(\beta)=1$.

So, the lower the hesitant degree, the higher is the accuracy of PFNs.

Definition 3. Let $\beta_{1}=P\left(\mu_{\beta_{1}}, \nu_{\beta_{1}}\right)$ and $\beta_{2}=P\left(\mu_{\beta_{2}}, v_{\beta_{2}}\right)$ be two PFNs. Let $S\left(\beta_{i}\right)_{(i=1,2)}$ and $h\left(\beta_{i}\right)_{(i=1,2)}$ be the score values and accuracy values of $\beta_{1}$ and $\beta_{2}$, respectively; then [46], 
(i) If $s\left(\beta_{1}\right)<s\left(\beta_{2}\right)$, then $\beta_{1}<\beta_{2}$;

(ii) If $s\left(\beta_{1}\right)=s\left(\beta_{2}\right)$, then

(i) If $h\left(\beta_{1}\right)<h\left(\beta_{2}\right)$, then $\beta_{1}<\beta_{2}$.

(ii) If $h\left(\beta_{1}\right)=h\left(\beta_{2}\right)$, then $\beta_{1}=\beta_{2}$. (iii) If $h\left(\beta_{1}\right)>h\left(\beta_{2}\right)$, then $\beta_{1}>\beta_{2}$.

Definition 4. Let $\beta_{1}=P\left(\mu_{\beta_{1}}, v_{\beta_{1}}\right)$ and $\beta_{2}=P\left(\mu_{\beta_{2}}, v_{\beta_{2}}\right)$ be two PFNs. Then, the Euclidean distance between $\beta_{1}$ and $\beta_{2}$ is [38]

$$
d\left(\beta_{1}, \beta_{2}\right)=\sqrt{\frac{1}{2}\left[\left(\left(\mu_{\beta 1}\right)^{2}-\left(\mu_{\beta 2}\right)^{2}\right)^{2}+\left(\left(v_{\beta 1}\right)^{2}-\left(v_{\beta 2}\right)^{2}\right)^{2}+\left(\left(\pi_{\beta 1}\right)^{2}-\left(\pi_{\beta 2}\right)^{2}\right)^{2}\right]} .
$$

Definition 5. Let $\beta_{1}=P\left(\mu_{\beta_{1}}, v_{\beta_{1}}\right)$ and $\beta_{2}=P\left(\mu_{\beta_{2}}, v_{\beta_{2}}\right)$ be two PFNs; then [38],
(i) $d\left(\beta_{1}, \beta_{2}\right)=d\left(\beta_{2}, \beta_{1}\right)$
(ii) $d\left(\beta_{1}, \beta_{2}\right)=0$ only if $\beta_{1}=\beta_{2}$
(iii) $0<d\left(\beta_{1}, \beta_{2}\right)<1$

\section{Procedure for Pythagorean Fuzzy TODIM}

Let $A_{i}$ be the alternative and $C_{j}$ be the criteria and PFN be expressed as $r_{i j}=P\left(\mu_{i j}, v_{i j}\right)$. Then, the Pythagorean fuzzy decision matrix is represented as $R=\left(r_{i j}\right)_{m x n}$

$$
R=\left[\begin{array}{cccc}
P\left(\mu_{11}, v_{11}\right) & P\left(\mu_{12}, v_{12}\right) & \ldots & P\left(\mu_{1 n}, v_{1 n}\right) \\
P\left(\mu_{21}, v_{21}\right) & P\left(\mu_{22}, v_{22}\right) & \ldots & P\left(\mu_{2 n}, v_{2 n}\right) \\
\vdots & \vdots & \ldots & \vdots \\
P\left(\mu_{m 1}, v_{m 1}\right) & P\left(\mu_{m 2}, v_{m 2}\right) & \ldots & P\left(\mu_{m n}, v_{m n}\right)
\end{array}\right],
$$

where the criteria are along the row and alternative along the column. We follow the steps as follows:

Step 1: we design the Pythagorean decision fuzzy matrix $R=\left(r_{i j}\right)_{m \times n}$, given by the decision maker

Step 2: we transform this matrix by using equation (3) from Section 2.3

Step 3: we then calculate the relative weight of each criterion $w_{j r}=w_{j} / w_{r}$, where $w_{j}$ is the weight of criteria $C_{j}$ and

$$
w_{r}=\max \{w j \mid, \quad j=1,2, \ldots, n\} .
$$

Step 4: we calculate the degree of dominance of each alternative $A_{i}$ over $A_{j}$ with respect to criterion $C_{j}$ by

$$
\varphi\left(A_{i}, A_{t}\right)= \begin{cases}\sqrt{\frac{w_{j r} d\left(l_{i j}, l_{t j}\right)}{\sum_{j=1}^{n} w_{j r}}} & l_{i j}>l_{t j}, \\ 0 & l_{i j}=l_{t j}, \\ -\frac{1}{\theta} \sqrt{\frac{\left(\sum_{j=1}^{n} w_{j r}\right) d\left(l_{i j}, l_{t j}\right)}{w_{j r}}} & l_{i j}<l_{t j},\end{cases}
$$

where $\theta$ is the attenuation factor of the loss and $d\left(l_{i j}, l_{t j}\right)$ is the distance between the PFN $l_{i j}$ and $l_{t j}$.

Using this above formula, we construct the dominance degree matrix, in order to show $\varphi_{j}=\varphi_{j}\left(A_{i}, A_{t}\right)_{m \times m}$ visually for $j=1,2, \ldots, n$.

$$
\varphi_{j}=\begin{gathered}
A_{1} \\
A_{2} \\
M
\end{gathered}\left[\begin{array}{cccc}
A_{1} & A_{2} & \cdots & A_{m} \\
0 & \varphi_{j}\left(A_{1}, A_{2}\right) & \wedge & \varphi_{j}\left(A_{1}, A_{m}\right) \\
\varphi_{j}\left(A_{2}, A_{1}\right) & 0 & \wedge & \varphi_{j}\left(A_{2}, A_{m}\right) \\
M & M & 0 & M \\
\varphi_{j}\left(A_{m}, A_{1}\right) & \varphi_{j}\left(A_{m}, A_{2}\right) & \wedge & 0
\end{array}\right] .
$$

Step 5: we then calculate the overall dominance degree by the formula

$$
\delta\left(A_{i}, A_{t}\right)=\sum_{j=1}^{n} \varphi_{j}\left(A_{i}, A_{t}\right) .
$$

Step 6: we then derive the overall value of each alternative $A_{i}$ by

$$
\xi_{i}=\frac{\sum_{t=1}^{m} \delta\left(A_{i}, A_{t}\right)-\min \left\{\sum_{t=1}^{m} \delta\left(A_{i}, A_{t}\right)\right\}}{\max _{i}\left\{\sum_{t=1}^{m} \delta\left(A_{i}, A_{t}\right)\right\}-\min _{i}\left\{\sum_{t=1}^{m} \delta\left(A_{i}, A_{t}\right)\right\}} .
$$

And the order of each alternative can be ranked by the principle, that is, the greater the overall value, the better the alternative.

Step 7: we determine the ranking of the alternatives according to the overall values.

\section{Numerical Example}

MSME is located in North India and is considered which practice inventory control policies (alternatives) like heuristics (heu), JIT, EOQ, and VMI. These policies were evaluated on the following criteria: raw material ordering frequency $\left(x_{1}\right)$, stock verification frequency $\left(x_{2}\right)$, production types $\left(x_{3}\right)$, inventory cost $\left(x_{4}\right)$, capital investment $\left(x_{5}\right)$, and demand $\left(x_{6}\right)$. The Pythagorean fuzzy set is an efficient extension of the intuitionistic fuzzy set, with membership and nonmembership values that fulfill the 
condition that the squared sum of these values is less than or equal to 1 [47]. Therefore, in this article, the Pythagorean fuzzy set is preferred over other existing fuzzy sets. Using proficient opinion, the membership degree $\mu_{i j}$ and nonmembership degree $v_{i j}, v_{i j}, v_{i j}$ [48-51] of the inventory policy concerning the criteria are expressed with the Pythagorean fuzzy decision matrix, as given in Table 1.

Similarly, the weights of the attributes are given as

$$
W=\left\{\begin{array}{l}
(0.30,0.65),(0.35,0.40),(0.25,0.25) \\
(0.50,0.35),(0.60,0.30),(0.55,0.25)
\end{array}\right\}
$$

Given the data and the weights, we apply the Pythagorean TODIM approach as follows:

Step 1: calculating the value of $S(\beta)$ function of each inventory policy with respect to the criteria using equation (3) is given as in Table 2

Step 2: by using the formula $w=\mu_{\beta}+\nu_{\beta}$, we defuzzify the given weights as $w=\{0.95,0.75,0.50,0.85,0.90$, $0.80\}$

Step 3: using equation (8) for each criterion, for instance, $w_{r}=\max (0.95,0.75,0.50,0.85,0.90,0.80)=$ 0.95

Taking criteria $x_{1}, w_{1}=0.95$ and $w_{1 r}=1$. The relative weights of other criteria would be $w_{2 r}=0.79, w_{3 r}=0.53$, $w_{4 r}=0.89, w_{5 r}=0.95$, and $w_{6 r}=0.84$.

Step 4: using equations (9) and (10), we create the dominance degree matrix for each criteria $x_{j}(j=1,2,3$, $4,5,6)$; let $\theta=2.5$, also heu $=A_{1}$, JIT $=A_{2}, \mathrm{EOQ}=A_{3}$, and $\mathrm{VMI}=A_{4}$ for simplicity purpose; then,

$$
\begin{aligned}
& \varphi_{1}=\begin{array}{c}
A_{1} \\
A_{2} \\
A_{3} \\
A_{4}
\end{array}\left[\begin{array}{cccc}
A_{1} & A_{2} & A_{3} & A_{4} \\
0 & -0.4581 & 0.1886 & -0.5198 \\
0.2290 & 0 & 0.2898 & 0.2001 \\
-0.3771 & -0.5797 & 0 & -0.5853 \\
0.2599 & -0.4003 & 0.2926 & 0
\end{array}\right] \text {, } \\
& \varphi_{2}=\begin{array}{c}
A_{1} \\
A_{2} \\
A_{3} \\
A_{4}
\end{array}\left[\begin{array}{cccc}
A_{1} & A_{2} & A_{3} & A_{4} \\
0 & 0.2022 & 0.1675 & 0.2447 \\
-0.5118 & 0 & -0.2997 & 0.1584 \\
-0.4241 & 0.1184 & 0 & 0.1943 \\
-0.6195 & -0.4010 & -0.4919 & 0
\end{array}\right] \text {, } \\
& \varphi_{3}=\begin{array}{c}
A_{1} \\
A_{2} \\
A_{3} \\
A_{4}
\end{array}\left[\begin{array}{cccc}
A_{1} & A_{2} & A_{3} & A_{4} \\
0 & 0.0829 & -0.2583 & 0.1140 \\
-0.3130 & 0 & -0.3935 & 0.0846 \\
0.0684 & 0.1043 & 0 & 0.1323 \\
-0.4300 & -0.3192 & -0.4994 & 0
\end{array}\right] \text {, }
\end{aligned}
$$

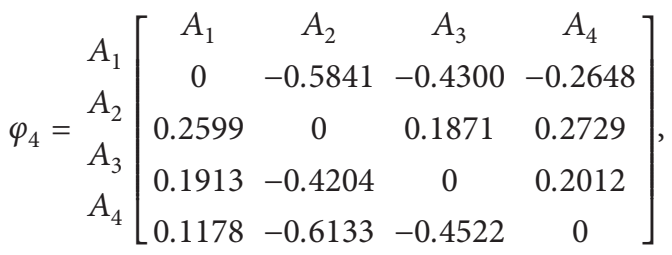

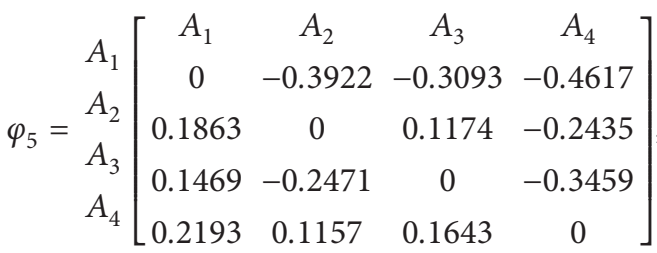

$$
\begin{aligned}
& \varphi_{6}=\begin{array}{c}
A_{1} \\
A_{2} \\
A_{3} \\
A_{4}
\end{array}\left[\begin{array}{cccc}
A_{1} & A_{2} & A_{3} & A_{4} \\
0 & 0.0894 & -0.3292 & 0.2315 \\
-0.2129 & 0 & -0.3621 & 0.2155 \\
0.1383 & 0.1521 & 0 & 0.2615 \\
-0.5512 & -0.5131 & -0.6226 & 0
\end{array}\right]
\end{aligned}
$$

Step 5: we calculate the overall degree of dominance using equation (11):

$$
\delta=\begin{gathered}
A_{1} \\
A_{2} \\
A_{3} \\
A_{4}
\end{gathered}\left[\begin{array}{cccc}
A_{1} & A_{2} & A_{3} & A_{4} \\
0 & -1.0599 & -0.9707 & -0.6561 \\
-0.3625 & 0 & -0.461 & 0.6880 \\
-0.2563 & -0.8724 & 0 & -0.1419 \\
-1.0037 & -2.1312 & -1.6092 & 0
\end{array}\right] .
$$

Step 6: determining the overall value of the alternatives using equation (12), we have

$$
\begin{array}{lllll}
\text { Alternatives } & A 1 & A 2 & A 3 & A 4 \\
\xi_{i} & 0.4464 & 1 & 0.7537 & 0
\end{array} .
$$

Therefore, ranking the candidates,

$$
\begin{aligned}
& A_{2}>A_{2}>A_{1}>A_{4} \\
& \quad \text { Or } \\
& \quad \text { JIT }>\text { EOQ }>\text { heu }>\text { VMI. }
\end{aligned}
$$

\section{Sensitivity Analysis}

The sensitivity analysis studied from [52] is formulated by taking randomly selected six different values of the attenuation factor. We discovered that the model is fairly stable after conducting a sensitivity analysis. We looked at several values of the attenuation factor $\theta$ to see how they affected the ranking. We discovered that there is no change in rank when the value is between 1 and 18 . We saw a minor change in rank after it, but they may be overlooked. In real life, the attenuation factor for raising the risk or difficulty level is unlikely to be greater than 18 . Table 3 provides the results we obtained when we selected these values of $\theta$ randomly. 
TABle 1: Pythagorean fuzzy decision matrix of inventory policy.

\begin{tabular}{lcccccc}
\hline & $x_{1}$ & $x_{2}$ & $x_{3}$ & $x_{4}$ & $x_{5}$ & $x_{6}$ \\
\hline heu & $0.6,0.25$ & $0.8,0.2$ & $0.75,0.1$ & $0.45,0.5$ & $0.6,0.3$ & $0.75,0.05$ \\
JIT & $0.8,0.15$ & $0.6,0.3$ & $0.7,0.25$ & $0.8,0.1$ & $0.75,0.2$ & $0.72,0.23$ \\
EOQ & $0.4,0.45$ & $0.68,0.2$ & $0.78,0.08$ & $0.65,0.25$ & $0.7,0.2$ & $0.82,0.1$ \\
VMI & $0.75,0.5$ & $0.45,0.5$ & $0.65,0.25$ & $0.4,0.45$ & $0.8,0.15$ & $0.45,0.5$ \\
\hline
\end{tabular}

TABLE 2: The value of $S(\beta)$ function of each inventory policy with respect to the criteria.

\begin{tabular}{lccccrr}
\hline & $x_{1}$ & $x_{2}$ & $x_{3}$ & $x_{4}$ & $x_{5}$ & 0.270 \\
\hline heu & 0.297 & 0.600 & 0.553 & 0.048 & 0.560 \\
JIT & 0.618 & 0.270 & 0.427 & 0.630 & 0.522 & 0.466 \\
EOQ & 0.042 & 0.422 & 0.602 & 0.360 & 0.450 & 0.662 \\
VMI & 0.560 & 0.048 & 0.360 & 0.042 & 0.618 & 0.048 \\
\hline
\end{tabular}

TABLE 3: The rankings obtained by change of value of the attenuation factor.

\begin{tabular}{lcccc}
\hline$\theta$ & heu & JIT & EOQ & VMI \\
\hline 1 & 3 & 1 & 2 & 4 \\
2.5 & 3 & 1 & 2 & 4 \\
9.23 & 3 & 1 & 2 & 4 \\
10.1 & 3 & 1 & 2 & 4 \\
15.48 & 3 & 1 & 2 & 4 \\
18 & 3 & 1 & 2 & 4 \\
\hline
\end{tabular}

\section{Correlation Analysis}

A correlation analysis [53] of ranking obtained by the three mathematical models GRA, VIKOR, and TODIM under Pythagorean fuzzy sets is discussed.

For better understanding, it should be known that the extreme values of correlation coefficient $(r),-1$ and 1 , indicate a perfect linear relationship when all the data points fall on a line. In practice, a perfect correlation, either positive or negative, is rarely observed. Values between 0 and $+1 /-1$ represent a scale of weak, moderate, and strong relationships. As $r$ gets closer to either -1 or 1 , the strength of the relationship increases. A coefficient of 0 indicates no linear relationship between the variables.

From Table 4, few concrete observations on correlation between the three methods can be made as follows:

(1) GRA and VIKOR are positively correlated, the correlation coefficient being 8. A strong positive correlation between these two models is due to the fact that both models had the same ranking for most alternatives.

(2) GRA and TODIM are positively correlated, the correlation coefficient being 4. A moderate positive correlation can be acknowledged because both of these models did not have the same ranking except for only one alternative.

Under Pythagorean fuzzy environment, we introduced different strategies for inventory policy selection problem. To compare the inventory ranking, we used three methods of
TABLE 4: Ranking obtained from GRA, VIKOR, and TODIM under Pythagorean fuzzy environment [54].

\begin{tabular}{lccc}
\hline & GRA & VIKOR & TODIM \\
\hline JIT & 4 & 3 & 2 \\
EOQ & 1 & 1 & 3 \\
HEU & 2 & 2 & 1 \\
VMI & 3 & 4 & 4 \\
\hline
\end{tabular}

GRA, VIKOR, and TODIM. GRA and TODIM provided the same results in ranking to some extent, while VIKOR's and TODIM's performance varied completely. The first rank of selection of inventory policy was for JIT, followed by EOQ. Rating for the heuristic and VMI inventory policies differed. In this dynamic environment, this study has provided an appropriate guide to coping with MCDM problems.

\section{Conclusion}

The TODIM method, built on the basis of the prospect principle, will effectively explain underrisk psychological actions of the decision maker, whereas the PFS is an efficient conceptual strategy for representing ambiguity. In this study, we have established the Pythagorean fuzzy TODIM method, which is useful to cope with the MCDM problems that in unclear circumstances consider the psychological activities of DMs. The simulation experiments were carried out to determine how the risk attitude influences the outcomes of the MCDM problems. The study has presented an appropriate guide to cope with MCDM issues in this dynamic environment, which can not only depict the confusion but can also reflect the dangerous psychological actions of DMs. Overall application of the Pythagorean fuzzy set in TODIM is easier to be computed in challenging scenarios and its generally constant sensitivity (Section 5). The reason for choosing over the VIKOR or GRA method $[54,55]$ is its medium computation procedure. Sensitivity analysis has been performed to check the stability of the model. In further analysis, the method would address the qualitative and quantitative details, which can also depict the ambiguity and the risk. 


\section{Data Availability}

The data used to support the findings of this study are included within the article.

\section{Conflicts of Interest}

The authors declare that they have no conflicts of interest.

\section{Authors' Contributions}

Dr. Prabjot Kaur developed methodology and software and supervised the study. Dr. Bijay Lal Pradhan conceptualized, validated, and performed formal analysis. Anjali Priya wrote the original draft and involved in data curation. All authors read and approved the final manuscript.

\section{Acknowledgments}

The authors extend their gratitude to Subhomoy Haldar and Vaishnudebi Dutta for supporting them in sensitivity analysis of the study.

\section{References}

[1] A. Rabbani, M. Zamani, and A. Yazdani-Chamzini, "Proposing a new integrated model based on sustainability balanced scorecard (SBSC) and MCDM approaches by using linguistic variables for the performance evaluation of oil producing companies," Expert Systems with Applications, vol. 41, no. 16, pp. 7316-7327, 2014.

[2] G. Kou, Y. Peng, and C. Lu, "MCDM approach to evaluating bank loan default models," Technological and Economic Development of Economy, vol. 20, no. 2, pp. 292-311, 2014.

[3] E. Mulliner, N. Malys, and V. Maliene, "Comparative analysis of MCDM methods for the assessment of sustainable housing affordability," Omega, vol. 59. , 2015 in press.

[4] M. Akbari, H. Memarian, E. Neamatollahi, M. Jafari Shalamzari, M. Alizadeh Noughani, and D. Zakeri, "Prioritizing policies and strategies for desertification risk management using MCDM-DPSIR approach in northeastern Iran," Environment, Development and Sustainability, vol. 23, no. 2, pp. 2503-2523, 2021.

[5] A. Ulutaş and Ç. Karaköy, "Evaluation of LPI values of transition economies countries with a grey MCDM model," in Handbook of Research on Applied AI for International Business and Marketing ApplicationsIGI Global, Pennsylvania, PA, USA, 2021.

[6] M. Li, L. Jin, and J. Wang, "A new MCDM method combining QFD with TOPSIS for knowledge management system selection from the user's perspective in intuitionistic fuzzy environment," Applied Soft Computing, vol. 21, pp. 28-37, 2014.

[7] E. Celik, A. T. Gumus, and M. Alegoz, "A trapezoidal type-2 fuzzy MCDM method to identify and evaluate critical success factors for humanitarian relief logistics management," Journal of Intelligent and Fuzzy Systems: Applications in Engineering and Technology, vol. 27, no. 6, pp. 2847-2855, 2014.

[8] S. Sakhuja, V. Jain, and F. Dweiri, "Application of an integrated MCDM approach in selecting outsourcing strategies in hotel industry," International Journal of Logistics Systems and Management, vol. 20, no. 3, pp. 304-324, 2015.
[9] A. Blagojević, S. Kasalica, Ž. Stević, G. Tričković, and V. Pavelkić, "Evaluation of safety degree at railway crossings in order to achieve sustainable traffic management: a novel integrated fuzzy MCDM model," Sustainability, vol. 13, no. 2, p. 832, 2021.

[10] N. P. Jesiya and G. Gopinath, "A fuzzy based MCDM-GIS framework to evaluate groundwater potential index for sustainable groundwater management-A case study in an urbanperiurban ensemble, southern India," Groundwater for Sustainable Development, vol. 11, Article ID 100466, 2020.

[11] Y. H. Hung, S. C. T. Chou, and G. H. Tzeng, "Knowledge management adoption and assessment for SMEs by a novel MCDM approach," Decision Support Systems, vol. 51, pp. 270-291, 2011.

[12] T. Gürbüz and Y. E. Albayrak, "An engineering approach to human resources performance evaluation: hybrid MCDM application with interactions," Applied Soft Computing, vol. 21, pp. 365-375, 2014.

[13] H. HaghshenasGorgani and A. R. J. Pak, "Identification of factors affecting quality of teaching engineering drawing using a hybrid MCDM model," Journal of AI and Data Mining, vol. 8, no. 2, pp. 247-267, 2020.

[14] S. HashemkhaniZolfani, R. Maknoon, and E. K. Zavadskas, "Multiple nash equilibriums and evaluation of strategies. New application of MCDM methods," Journal of Business Economics and Management, vol. 16, no. 2, pp. 290-306, 2015.

[15] A. M. Ghaleb, H. Kaid, A. Alsamhan, S. H. Mian, and L. Hidri, "Assessment and comparison of various MCDM approaches in the selection of manufacturing process," Advances in Materials Science and Engineering, vol. 20, 2020.

[16] C. L. Hwang and K. S. Yoon, Multiple Attribute Decision Methods and Applications, Springer, Berlin, Germany, 1981.

[17] B. Roy and P. Bertier, La méthode ELECTRE II: une méthode de classement en prédence de critères multiples, 1971.

[18] B. Mareschal, J. P. Brans, and P. Vincke, PROMETHEE: A New Family of Outranking Methods in Multi Criteria Analysis, ULB, Universite Libre de Bruxelles, Berlin, Germany, 1984.

[19] D. Kahneman and A. Tversky, "Prospect theory: an analysis of decision under risk," Econometrica: Journal of the Econometric Society, vol. 47, pp. 263-291, 1979.

[20] M. Abdellaoui, H. Bleichrodt, and C. Paraschiv, "Loss aversion under prospect theory: aparameter-free measurement," Management Science, vol. 53, pp. 1659-1674, 2007.

[21] L. Gomes and M. Lima, "TODIM: basics and application to multicriteria ranking of projects with environmental impacts," Foundations of Computing and Decision Sciences, vol. 16, pp. 113-127, 1991.

[22] L. A. Zadeh, "Fuzzy sets," Information and Control, vol. 8, pp. 338-353, 1965.

[23] R. E. Bellman and L. A. Zadeh, "Decision-making in a fuzzy environment," Management Science, vol. 17, pp. 141-161, 1970.

[24] R. R. Yager, "Fuzzy decision making including unequal objectives," Fuzzy Sets and Systems, vol. 1, pp. 87-95, 1978.

[25] K. Nakamura, "Preference relations on a set of fuzzy utilities as a basis for decision making," Fuzzy Sets and Systems, vol. 20, pp. 147-162, 1986.

[26] K. T. Atanassov, "Intuitionistic fuzzy sets," Fuzzy Sets and Systems, vol. 20, pp. 87-96, 1986.

[27] Z. S. Xu and R. R. Yager, "Dynamic intuitionistic fuzzy multiattribute decision making," International Journal of Approximate Reasoning, vol. 48, pp. 246-262, 2008. 
[28] H. W. Liu and G. J. Wang, "Multi-criteria decision-making methods based on intuitionistic fuzzy sets," European Journal of Operational Research, vol. 179, pp. 220-233, 2007.

[29] F. E. Boran, S. Genç, M. Kurt, and D. Akay, "A multi-criteria intuitionistic fuzzy group decision making for supplier selection with TOPSIS method," Expert Systems with Applications, vol. 36, Article ID 11363, 2009.

[30] R. R. Yager, "Pythagorean fuzzy subsets," in Proceedings of the Joint IFSA World Congress and NAFIPS Annual Meeting, pp. 57-61, Edmonton, Canada, June 2013.

[31] R. R. Yager, "Pythagorean membership grades in multicriteria decision making," IEEE Transactions on Fuzzy Systems, vol. 22, pp. 958-965, 2014.

[32] L. H. Chen, C. C. Hung, and C. C. Tu, "Considering the decision maker's attitudinal character to solve multi-criteria decision-making problems in an intuitionistic fuzzy environment," Knowledge-Based Systems, vol. 361, pp. 29-38, 2012.

[33] H. C. Liu, J. X. You, X. J. Fan, and Y. Z. C, "Site selection in waste management by the VIKOR method using linguistic assessment," Applied Soft Computing, vol. 214, pp. 53-61, 2014.

[34] J. Wu and F. Chiclana, "A risk attitudinal ranking method for interval-valued intuitionistic fuzzy numbers based on novel attitudinal expected score and accuracy functions," Applied Soft Computing, vol. 222, pp. 72-86, 2014.

[35] X. Tian, W. Li, L. Liu, and G. Kou, "Development of TODIM with different types of fuzzy sets: a state-of the-art survey," Applied Soft Computing, vol. 111, Article ID 107661, 2021.

[36] R. A. Krohling and T. T. M. D. Souza, "Combining prospect theory and fuzzy numbers to multi-criteria decision making," Expert Systems with Applications, vol. 39, Article ID 11487, 2012.

[37] Z. P. Fan, X. Zhang, F. D. Chen, and Y. Liu, "Extended TODIM method for hybrid multiple attribute decision making problems," Knowledge-Based Systems, vol. 42, pp. 40-48, 2013.

[38] P. Ren, Z. Xu, and X. Gou, "Pythagorean fuzzy TODIM approach to multi-criteria decision making," Applied Soft Computing Journal, vol. 42, pp. 246-259, 2016.

[39] D. Mohammaditabar, S. H. Ghodsypour, and C. O. Brien, "Inventory control system design by integrating inventory classification and policy selection," International Journal of Production Economics, vol. 140, pp. 655-659, 2012.

[40] F. Arikan and S. Citak, "Multiple criteria inventory classification in an electronics firm," International Journal of Information Technology and Decision Making, vol. 16, pp. 1-17, 2017.

[41] Y. Li, Y. Shan, and P. Liu, "An extended TODIM method for group decision making with the interval intuitionistic fuzzy sets," Mathematical Problems in Engineering, vol. 2015, Article ID 672140, 9 pages, 2015.

[42] R. A. Krohling, A. G. Pacheco, and A. L. Siviero, "IF-TODIM: an intuitionistic fuzzy TODIM to multi-criteria decision making," Knowledge-Based Systems, vol. 53, pp. 142-146, 2013.

[43] L. Wang, Y. M. Wangand, and L. Martínez, "Fuzzy TODIM method based on alpha-level sets," Expert Systems with Applications, vol. 140, Article ID 12889, 2020.

[44] X. Peng and Y. Yang, "Some results for pythagorean fuzzy sets," International Journal of Intelligent Systems, vol. 30, no. 11, pp. 1133-1160, 2015.

[45] X. Zhang and Z. Xu, "Extension of TOPSIS to multiple criteria decision making with Pythagorean fuzzy sets," International
Journal of General Systems, vol. 29, no. 12, pp. 1061-1078, 2014.

[46] X. Peng and Y. Yang, "Pythagorean fuzzy Choquet integral based MABAC method for multiple attribute group decision making," International Journal of Intelligent Systems, vol. 31, no. 10, pp. 989-1020, 2016.

[47] A. Guleria and R. K. Bajaj, "Pythagorean fuzzy-norm information measure for multicriteria decision-making problem," Advances in Fuzzy Systems, vol. 2018, Article ID 8023013, 11 pages, 2018.

[48] D. F. Li, "Extension of the LINMAP for multiattribute decision making under Atanassov's intuitionistic fuzzy environment," Fuzzy Optimization and Decision Making, vol. 7, no. 1, pp. 17-34, 2008.

[49] D. F. Li, Decision and Game Theory in Management with Intutionistic Fuzzy Sets, Springer, Berlin, Germany, 2014.

[50] P. Kaur, V. Dutta, B. L. Pradhan, S. Haldar, and S. Chauhan, "A pythagorean fuzzy approach for sustainable supplier selection using TODIM," Mathematical Problems in Engineering, vol. 2021, Article ID 4254894, 11 pages, 2021.

[51] B. L. Pradhan, "Confirmatory factor analysis of TQM implementation constructs: evidence from Nepalese manufacturing industries," Management Review: International Journal, vol. 12, no. 1, p. 26, 2017.

[52] M. Li, C. Wu, and L. Zhang, "An intuitionistic fuzzy-TODIM method to solve distributor evaluation and selection problem," International Journal of Simulation Modelling, vol. 14, pp. 511-524, 2015.

[53] S. C. Gupta and V. Kapoor, Fundamentals of Mathematical Statistics, Sultan Chand and sons, New Delhi, India, 2020.

[54] P. Kaur and P. Anjali, "Selection of inventory policy under pythogrean fuzzy environment," Science \& Technologie Alimentaire, vol. 25, no. 1, pp. 62-71, 2020.

[55] S. Vakilipour, A. Sadeghi-Niaraki, M. Ghodousi, and S. M. Choi, "Comparison between multi-criteria decisionmaking methods and evaluating the quality of life at different spatial levels," Sustainability, vol. 13, no. 7, 2021. 